\title{
The Effects of Recreational Activities on Depressive Symptoms and Burnout Level of Mothers of Children with Autism Spectrum Disorders
}

\author{
Eren ŞAHIN $^{1}$, Ahmet Onur ÖZ ${ }^{2}$, R. Hürrem Ö
${ }^{1-2}$ Institue of Health Sciences, Hitit University, Çorum, Turkey \\ ${ }^{4}$ Faculty of Sport Sciences, Inonu University, Malatya, Turkey \\ *Corresponding author: hurremozdurak@hitit.edu.tr
}

\begin{abstract}
Several studies revealed some mood disorders such as depression and burnout in nursing parents as a result of difficulties brought by Autism Spectrum Disorder (ASD) symptoms. On the other hand, recreative activities have a therapeutic effect on mental health. The aim of the study was to determine the effect of physical activity-based recreation on mothers' depression and burnout levels. Fifteen mothers of children with ASD were included in the single-group pre-test and post-test experimental design study. Beck Depression Inventory and Maslach Burnout Inventory were applied to mothers to determine depression and burnout levels before and after the one-week camp. According to the results of the paired sample t-test, the depression levels of the mothers decreased significantly after the camp, whereas burnout levels remained the same. While depression and burnout levels of the mothers were moderately correlated before the recreation camp, they did not correlate following the recreation camp. It can be concluded that burnout emotional state in parents of children with ASD may correlate with depression which that might be reduced as a result of physical activity based recreative activities. Further longitudinal studies including quantitative and qualitative research methods are needed to determine the cause-effect relationship and create effective recreational programs for families of children with ASD.
\end{abstract}

Keywords

Recreation, Autism Spectrum Disorder, Burnout, Depression, Mother

\section{INTRODUCTION}

Recreation is termed as spare time and/or leisure activities to improve the quality of life of the individual (Aydın \& Tütüncü, 2018). Recreation is renamed as therapeutic recreation if it serves to slows or stops the progression of any disease or in case of disability. Moreover, it contributes to the treatment process in order to increase the quality of life of the individuals and affects the psychological well-being (Aydin \& Tütüncü, 2018; Tütüncü, 2012; Tütüncü \& Aydın, 2016). Studies have shown that recreational activities offer benefits to individuals who feel social and psychological discomfort (Williams \& Bond, 2002). There are also physical activities that are frequently involved in recreation activities. Physical activities play a role in the well-being and health of individuals and society (Demirci et al., 2018). Depression, anxiety, and burnout are the most studied and well-known mental health components affected by disability and might be lowered or even healed by recreational activities (Carruthers \& Hood, 2007; Sylvester, 2014; Vella, Milligan \& Bennett, 2013; Williams \& Bond, 2002). 
Autism spectrum disorder (ASD) is a neurodevelopmental disorder that has been categorized with inadequate social-communicative disorders, limited-repetitive behaviors, and limited interests (American Psychiatric Association [APA], 2013). The prevalence of ASD mostly diagnosed at early childhood has been increasing year by year. The report published by CDC (Centers for Disease Control and Prevention) indicated that 1 out of 54 children are born with the risk of ASD (Maenner et al., 2020). Several negative effects on family's psychological parameters due to the difficulties brought by the symptoms of ASD has been demonstrated in literature and became an important topic in public health research (Turnbull et al., 2007). Families often do not know how to face with and handle the difficulties and problems that has been experienced by their children with ASD. Struggling in finding solutions becomes very corrosive to the family, thus heavy load of responsibilities may lead to mental health problems such as depression, burnout, and stress (Darica et al., 2017).

Depression is not just a spiritual breakdown, more precisely it is a mental disease that is quite complicated in terms of its causes, course, and treatment. In general, depression is a syndrome that includes symptoms such as slowness in thought, speech, and movement, stagnation, fatigue, decreased attention and concentration, decreased reluctance and motivation, lack of worthiness, guilt, pessimism, and slowing of physiological functions in a deeply sad mood (Şireli \& Soykan, 2016). On the other hand, the concept of burnout was first introduced to the literature by Freudenberger in 1974. He expressed burnout as a loss of energy resulting from wearing out and overload (Freudenberger, 1974). Burnout consists of three sub-dimensions which are emotional burnout, depersonalization, and a feeling of falling in personality success.

Emotional burnout is expressed as the most critical dimension with symptoms such as lack of energy and feeling wearing out. Depersonalization is characterized as the lack of individuals' emotion, being cynical, and with disdainful behavior towards others (Kaçmaz, 2005; Leiter \& Maslach, 1988; Singh et al., 1994;). Burnout can cause serious physical and mental problems in individuals. This situation paves the way for depressive symptoms. The desperate and moody mood that occurs in a depressed state affects daily life and interpersonal relationships (Çam, 1991; Dignam et al., 1986).

Families of children with ASD experience more stress and depression and lower overall family functions due to the variety of ASD symptoms (Benjak et al., 2011; Hayes \& Watson 2013; Khanna et al., 2011). Weiss (2002) stated that families with children with ASD are more affected by depression, anxiety, somatic complaints, and burnout compared to other disability groups, thus parents' psychological problems are severe in ASD (Chiri \& Warfield, 2012; Dabrowska \& Pisula 2010; Estes et al. 2009; Sikora et al. 2013).

Krausz and Meszaros (2005) identified that being a mother of a child with ASD has a greater negative effect on the quality of life of the mother rather than fathers, since care for children is undertaken by women as a result of cultural expectations (Hastings et al. 2005; Sayer, 2005). Caring for a child with ASD with destructive behavior, anger attacks, and routine and social skills deficiencies can lead to anxiety, stress, and depression over time (Elçi, 2004; Gürbüz-Özgür, Aksu \& Eser, 2017). Thus, various consequences of ASD in children may worsen mothers stress (Dabrowska \& Pisula, 2010), depression (Hastings et al. 2005), and anxiety (Hastings, 2003). The higher stress and burnout level indicate that social support is needed for parents of children with ASD (Lai \& Oei, 2014; Sikora et al. 2013).

The aim of the study is to determine the effect of a one-week recreation activity program (RAP) on depression and burnout levels of mothers of children with ASD. It has been hypnotized that recreational activity program may reduce (a) depression and (b) burnout in mothers of children with ASD. It is also argued that depressive symptoms and burnout levels of mothers may correlate as a result of ASD.

\section{MATERIALS AND METHODS}

The study was performed as a single group pre-test post-test experimental design with the approval of the non-interventional research ethics committee of Inonu University (No. 2020-376-03). All participants signed to a written informed consent form before the study. 


\section{Participants}

Twenty-eight mothers who are members of non-governmental organizations operating for families with ASD individuals were invited to this study. The criteria sampling method was used to select the participants. Inclusion criteria of the study; (a) being healthy and volunteering to participate in the research, (b) having a child of school age (7-18 years old), (c) child is diagnosed medically as moderate and severe ASD. (d) medical diagnosis is confirmed by Gilliam Autism Rating Scale-2-Turkish Version (GARS-2-TV).
GARS-2-TV is a rating scale used to assess individual behaviors specific to autistic disorder and is very strong in assessing and grading autistic symptoms of individuals with ASD (Diken et al., 2012). GARS-2-TV was applied to all children by a specialist practitioner to verify the ASD levels of children before the implementation period. Fifteen mothers met these criteria and volunteered to take part in the study. The demographic data of the participants obtained by personal information forms are presented in Table 1.

Table 1. Demographic data of the mothers of children with ASD

\begin{tabular}{|c|c|c|}
\hline Variables & Frequency $(f)$ & Percent (\%) \\
\hline \multicolumn{3}{|c|}{ Children, Age; $\bar{X} \pm S D: 11.7 \pm 2.7$} \\
\hline $7-12$ & 10 & 66.7 \\
\hline $13-18$ & 5 & 33.3 \\
\hline \multicolumn{3}{|l|}{ Gender } \\
\hline Girl & 2 & 13.3 \\
\hline Boy & 13 & 86.7 \\
\hline \multicolumn{3}{|l|}{ Level of ASD } \\
\hline Modarate & 7 & 46.7 \\
\hline Severe & 8 & 53.3 \\
\hline \multicolumn{3}{|c|}{ Mothers, Age; $\bar{X} \pm S D: 39.9 \pm 5.96$} \\
\hline \multicolumn{3}{|c|}{ Level of education } \\
\hline Primary school & 10 & 66.7 \\
\hline High school & 3 & 20 \\
\hline Undergraduate & 2 & 13.3 \\
\hline \multicolumn{3}{|l|}{ Income } \\
\hline Low & 3 & 20.0 \\
\hline Moderate & 8 & 53.3 \\
\hline High & 4 & 26.7 \\
\hline
\end{tabular}

$\overline{\bar{X}}$ : Mean, $S D$ : Standart Deviation

\section{Procedure and Research Design}

The camp team together with all mothers and children arrived in Kayseri Mountain Camp Center by bus. A recreation activity program started with the participation of 15 mothers and their children with ASD, 2 special education specialists and 15 volunteer students of Sports Sciences faculty. During the camp, group and individual physical exercise-based educational games and art activities such as painting, and music are applied for children with ASD. Recreative Activity Program (RAP) for mothers consists of both individual and group activities such as dancing, hiking, creative drama, physical exercise, winter sled. Pre-test and post-test were performed immediately before and after the one-week physical activity-based recreational activity program.

\section{Data Collection Tools}

Data was collected with (a) the Beck Depression Inventory (BDI) and (b) Maslach Burnout Inventory (MBI) for depression and burnout symptoms respectively at the first day and last day of the one-week RAP. 


\section{Beck Depression Inventory (BDI)}

Beck Depression Inventory (BDI) was developed by Beck (1967) and adapted to Turkish by Hisli (1989). BDI contains 21 items that assess cognitive, behavioral, affective, and somatic components of depression symptoms. It consists of 21 multiple-choice items, which has four levels sorted by symptom intensity. Each item is scored on a scale of 0 to 3 . BDI has high internal consistency with alpha coefficients ranging from .73 to .92 at the original form (Beck et al., 1988) and alpha coefficient of .80 at the Turkish adaptation form (Hisli, 1989).

\section{Maslach Burnout Inventory (MBI)}

The Maslach Burnout Inventory developed by Maslach \& Jackson (1981) and was adapted to Turkish by Çam (1991). Duygun and Sezgin (2003) adapted to evaluate the level of burnout in mothers of children with mental disabilities (Cronbach alpha, .80). The inventory consists of 22 items. This scale is a Likert type scale and one of the options 0 to 4 is marked according to the intensity of emotion in each item.

\section{Statistical Analysis}

Statistical analysis was performed by using the IBM (SPSS for MacOS ver. 25.0, Armonk,
NY: USA) statistical package program. ShapiroWilk test was used to check the normality of distribution. Differences in depression and burnout before and after the recreation activity camp were compared by using the Paired-sample t-Test in mothers of children with ASD. Pearson Correlation Coefficient was used to determine the relationship between depression and subgroups of burnout of mothers. The level of statistical significance was set at $\mathrm{p}<, 05$.

\section{RESULTS}

Descriptive statistics are given the depressive symptoms of mothers of children with ASD before and after the recreation camp are presented in Table 2 as frequency and percentage. It showed that $6.7 \%$ of mothers before RAP had severe, $73.3 \%$ had moderate, $6.7 \%$ had mild and $13.3 \%$ had minimal symptoms of depression. The program applied at the camp significantly reduced the depressive symptoms of the mothers, so that the symptoms of severe depression disappeared completely between the mothers. The moderate, mild and minimal depression symptoms were observed to change to $6.7 \%, 13.3 \%$, and $80 \%$ respectively.

Table 2. Depressive symptoms of mothers of children with ASD before and after recreational activity program.

\begin{tabular}{lcccc}
\hline & & Pre-test & \multicolumn{2}{c}{ Post-test } \\
\hline Depressive symptoms & $f$ & $\%$ & $f$ & $\%$ \\
Severe & 1 & 6.7 & 0 & 0 \\
Moderate & 11 & 73.3 & 1 & 6.7 \\
Mild & 1 & 6.7 & 2 & 13.3 \\
Minimal & 2 & 13.3 & 12 & 80 \\
\hline
\end{tabular}

Table 3. Differences in depression and burnout levels of mothers of children with ASD between pretests and posttest values.

\begin{tabular}{|c|c|c|c|c|}
\hline & Pre-test $(n=15)$ & Post-test $(n=15)$ & \multicolumn{2}{|c|}{ t-test } \\
\hline & $\bar{X} \pm S D($ Min-Max $)$ & $\overline{\bar{X}} \pm S D($ Min-Max $)$ & $T$ & $p$ \\
\hline BDI & $18.47 \pm 6.59(4-31)$ & $7.29 \pm 4.49(0-18)$ & 7.734 & $.001 *$ \\
\hline MBI & $37.8 \pm 7.07(20-45)$ & $37.8 \pm 11.44(3-52)$ & .001 & .99 \\
\hline
\end{tabular}

*p<.05, statistically significant difference. BDI: Beck Depression Inventory, MBI: Maslach Burnout Inventory.

Depression of mothers decreased significantly after recreational activities $(\mathrm{p}=.001, \mathrm{p}<.05)$, whereas burnout remained same $(\mathrm{p}=.99, \mathrm{p}>.05)$ when post-test values are compared to pre-test values (Table 3). According to Pearson Correlation Coefficient test, there was a moderate positive correlation between depression and burnout values $(\mathrm{r}=.07 ; \mathrm{p}=.03)$ before the RAP, however, this was diminished after RAP and no significant correlation was observed in post-test values $(\mathrm{r}=.09$; $\mathrm{p}=.56)$. 


\section{DISCUSSION}

This study determined the effect of RAP on depression and burnout of mothers of children with ASD. According to the result of the present study, BDI scores showing severe and moderate depressive symptoms of mothers decreased significantly after RAP. On the other hand, MBI scores of mothers of children with ASD remained same and did not change as a result of RAP. Therefore, it can be argued that a one-week RAP might have positive effect on depression and may reduce the depressive symptoms of mothers and has a positive impact on mental health that is restricted only to depression, but not on burnout. Since the RAP was mainly based on physical activity and exercise, it can be suggested that depressive symptoms of mothers decreased significantly as a result of increased physical activity levels during the one-week RAP.

These results are supported by literature, which demonstrates that physical activity and exercise have positive effect on depression with a variety of underlying causes (Dinas et al. 2011; Patten et al., 2009). It has been stated that recreational activities based on physical exercise positively affect the psychological well-being of mothers of children with physical, mental, and emotional disabilities (Columna et al., 2011). On the other hand, burnout levels of mother remained same despite the one-week RAP. Although there are several studies indicating that recreational and physical activities have positive effect on burnout and correlate to occupational burnout intensity (Erol \& Yazıcıŏlu, 2019; Toker \& Biron, 2012). Studies focusing on the impact of physical exercise-based recreational activity on burnout levels in families of children with ASD or another disability are limited.

Several studies focused on burnout levels and workload of professional caregivers for the children with ASD. It was found that burnout levels of these professional employees working in the caregiving service was high and correlated with the working time (Bottini et al., 2020). In order to decrease the burnout levels, the intensity of work and care burdens need to be reduced over time, and the qualifications of the caregiver were found to be directly related to the burnout levels of the individuals (Leiter \& Maslach, 2004). Taken all these findings together, it might be suggested that either the support given during RAP was insufficient in supporting families with pedagogical content to increase their qualification in care-giving to ASD in order to reduce the burnout level, or the duration of the program was not long enough to palliate the burnout (Demirtaş et al., 2019; Russell, 1987; Russell, 1990). This might also explain the difference in the correlation of BDI and MBI values of mothers before and after the one-week RAP, since only depression improved within one week whereas burnout levels remained same.

These findings are not in line with the results of the study performed by According to Tel and Ertekin-Pınar (2013), the risk of depression increases as burnout levels increase. Because, primer caregivers may experience psychological, emotional distress in the caregiving process, and these situations can lead to burnout. It can be argued that physical activity based recreation is sufficient to improve depressive disorders in mothers of children with ASD, but it is not sufficient to cope with burnout levels mostly caused by hopelessness, stress, anxiety and inconsistent relationship and cycle in the family as a result of health-related conditions of a child with ASD (Falk et al., 2014; Kim et al., 2016; Tunçel, 2017; Tunçel et al., 2018; Şahin, 2010). Another important argument might be inadequacy of measurement and evaluation of burn out levels in caregivers for individuals with disability.

The MBI was developed to measure the burn out level of individuals based on heavy workload and wearing out in daily life and therefore may not be adequate enough to measure the burn out level specific for caregivers who work for and/or have children with disabilities. Thus, heavy workload may be handled easier and solved within time, whereas concerns of families of children with disability differ in many aspects that has to be taken into consideration. Further detailed studies are needed to overcome this challenge, whereas some researchers suggested to reverse some scale items in order to eliminate this problem and increase the correctively of the assessment of burnout levels of families with MBI (Tunçel et al., 2018).

Despite the valuable findings obtained in this study, it must be taken into consideration that the burnout levels of mothers of children with ASD could not be assessed with all its subdimensions 
and is, therefore, a critical limitation of this study that can be overcome in future with a new burnout inventory or scale developed for families of disabled children. Another limitation might be the absence of a control group. However, it would not be ethical to host a control group without inclusion in the activities. This limitation will be replaced in future studies with a quasi-experimental research design. Further detailed qualitative and quantitative longitudinal research is needed to develop recreation programs for both children and families in order to offer social support and social inclusion for ASD. These studies should include a high degree of recreational group activities under the supervision of specialists in the field that will also support the family in pedagogical knowledge in theory and practice.

\section{REFERENCES}

American Psychiatric Association (2013). Diagnostic and Statistical Manual of Mental Disorders (5th ed.). Washington, DC.

Aydın, İ. (2018). Assessment of social effects of recreation therapy camps. Anatolia: Journal of Tourism Research, 29(1). 106-112. doi:10.17123/atad.441192

Aydın, İ., \& Tütüncü, Ö. (2018). Evaluation of Social Effects of Recreation Therapy Camps. Anatolia: Journal of Tourism Research, 29(1). 106-112. doi: 10.17123/atad.441192

Beck, A. T., Steer, R. A., \& Garbin, M. G. (1988). Psychometric properties of the Beck Depression Inventory: Twenty-five years of evaluation. Clinical Psychology Review, 8(1). 77-100. doi:10.1016/02727358(88)90050-5

Beck, A.T. (1967). Depression: Clinical, experimental and theoretical aspects. Hoeber: New York.

Benjak, T., Vuletic, G., \& Kolaric, B. (2011). Subjective quality of life for parents of children with autism spectrum disorders in Croatia. Applied Research in Quality of Life, 6(1), 91-102. doi:10.1007/s11482010-9114-6

Bottini, S., Wiseman, K., \& Gillis, J. (2020). Burnout in providers serving individuals with ASD: The impact of the workplace. Research in Developmental Disabilities, 100, 103616. doi:10.1016/j.ridd.2020.103616
Çam, O. (1991). Investigation of burnout syndrome among nurses (Unpublished $\mathrm{PhD}$ thesis). Ege University, İzmir.

Carruthers C.P., \& Hood, C. D. (2007). Building a life of meaning through therapeutic recreation: The leisure and well-being model part I, Therapeutic Recreation Journal, 41(4), 276-297.

Chiri, G., \& Warfield, M. E. (2012). Unmet Need and Problems Accessing Core Health Care Services for Children with Autism Spectrum Disorder. Maternal and Child Health Journal, 16(5), 1081-1091. doi:10.1007/s10995-011-0833-6

Columna, L., Pyfer, J., \& Senne, T. A. (2011). Physical recreation among immigrant Hispanic families with children with disabilities. Therapeutic Recreation Journal, 45(3), 214-233. https://search.proquest.com/openview/402cc4 b3eb7461200be58762f5c50d9e/1?cbl=5997\& pq-origsite $=$ gscholar

Dabrowska, A., \& Pisula, E. (2010). Parenting stress and coping styles in mothers and fathers of pre-school children with autism and Down syndrome. Journal of Intellectual Disability Research, 54, 266280 . doi:10.1111/j.13652788.2010.01258.x

Darıca N., Gümüşçü-Tuş Ş. \& Abdioğlu-Pişkin Ü. (2017). Autism and Autistic Children (6th ed.). Özgür Publications: İstanbul.

Demirci, N., Yıldırım, İ., Toptaş Demirci, P., \& Ersöz, Y. (2018). Why should we do physical activity? More active people for a healthier world. International Journal of Disabilities Sports and Health Sciences, 1(2), 1-14. doi:10.33438/Ijdshs.488292

Demirtaş, Ö., Şahin, E., \& Atl, F. (2019). Investigation of Factors Affecting Quality of Life and Participation in Recreation Activities of Caregivers with Autism Spectrum Disorder Individuals. Oral Presentation at 17. International Sport Sciences Congress, Antalya-Turkey. p. 2352-2352. http://burkonturizm.com/duyuru/burkon/82/S BK2019.pdf

Dignam, J.T., Barrera, M., \& West, S.G (1986). Occupational stress, social support, and burnout among correctional officers. American Journal of Community Psychology, 14(2), 177-193. doi:10.1007/bf00911820 
Diken, İ., Ardıç, A., Diken, Ö., \& Gilliam, J. (2012). Exploring the validity and reliability of Turkish version of Gilliam Autism Rating Scale-2: Turkish standardization study. Education and Science, $\quad 37(166), \quad 318-320$. http://egitimvebilim.ted.org.tr/index.php/ EB/article/view/1924/460

Dinas, P.C., Koutedakis, Y., \& Flouris, A. D. (2011). Effects of exercise and physical activity on depression. Irish Journal of Medical Science, 180(2), 319-325. doi:10.1007/s11845-0100633-9

Duygun, T., \& Sezgin, N. (2003). The effects of stress symptoms, coping styles and perceived social support on burnout level of mentally handicapped and healthy children's mothers. Turkish Journal of Psychology, 18(52), 37-52.

Elçi, Ö. (2004). Predictive values of social support, coping styles and stress level in posttraumatic growth and burnout levels among the parents of children with autism (Unpublished master thesis). Middle East Technical University, Ankara.

Erol, E. \& Yazıcıŏlu, İ. (2019). Mediating role of recreational activities in the effect of burnout level on business performance: A research in food and beverage businesses. Tourism Academic Journal, 6 (2), 139-152. https://dergipark.org.tr/tr/download/articlefile/868907

Estes, A., Munson, D., Dawson, G, Koehler, E., Zhou, X., \& Abbot, R. (2009). Parenting stress and psychological functioning among mothers of preschool children with autism and developmental delay [Turkish]. Autism, 13(4). 375-387. doi:10.1177/1362361309105658.

Falk, N., Norris, K., \& Quinn, M. G (2014). The factors predicting stress, anxiety and depression in the parents of children with autism. Journal of Autism and Developmental Disorders, 44(12), 3185-3203. doi:10.1007/s10803-014-2189-4

Freudenberger, H. J. (1974). Staff Burn-Out. Journal of Social Issues, 30(1), 159-165. doi:10.1111/j.15404560.1974.tb00706.x

Gürbüz-Özer, B., Aksu, H., \& Eser, E. (2017). Turkish validity and reliability of quality of life in autism questionnaire-parent version. Anatolian Journal of Psychiatry, 18(4). 344-352. doi:10.5455/apd.249390

Hastings, R. P. (2003). Child behavior problems and partner mental health as correlates of stress in mothers and fathers of children with autism. Journal of Intellectual Disability Research, 47(4- 5), 231-237. doi:10.1046/j.1365-2788.2003.00485.x

Hastings, R. P., Kovshoff, H., Brown, T., Ward, N. J., Espinosa, F. D., \& Remington, B. (2005). Coping strategies in mothers and fathers of preschool and school-age children with autism. Autism: The International Journal of Research and Practice, $\quad 9(4) \quad 377-391$. doi:10.1177/1362361305056078

Hayes, S. A., \& Watson, S. L. (2013). The impact of parenting stress: A meta-analysis of studies comparing the experience of parenting stress in parents of children with and without autism spectrum disorder. Journal of Autism and Developmental Disorders, 43(3), 629642. doi:10.1007/s10803-012-1604-y

Hisli, N. (1989). Validity and reliability of Beck Depression Inventory for university students. Turkish Psychological Journal, 7(23), 3-13.

Kaçmaz, N. (2005). Burnout syndrome. Journal of Istanbul Faculty of Medicine, 68(1), 29-32. https://dergipark.org.tr/tr/pub/iuitfd/issue/9260/ 116046

Khanna, R., Madhavan, S. S., Smith, M. J., Patrick, J. H., Tworek, C., \& Becker-Cottrill, B. (2011). Assessment of health-related quality of life among primary caregivers of children with autism spectrum disorders. Journal of autism and developmental disorders, 41(9), 12141227. doi:10.1007/s10803-010-1140-6

Kim, I., Ekas, N. V. \& Hock, R. (2016). Associations between child behavior problems, family management, and depressive symptoms for mothers of children with autism spectrum disorder. Research in Autism Spectrum Disorders, 26, 80-90. doi:10.1016/j.rasd.2016.03.009

Krausz, M. \& Meszaros, J. (2005). The retrospective experiences of a mother of a child with autism. The International Journal of Special Education, 20(2), 36-46. https://files.eric.ed.gov/fulltext/EJ846933.pdf

Lai, W. W., \& Oei, T. P. S. (2014). Coping in parents and caregivers of children with autism spectrum disorders (ASD): A review. Review Journal of Autism and Developmental Disorders, 1(3). 207-224. doi:10.1007/s40489-014-0021-x 
Leiter, M. P., \& Maslach, C. (1988). The impact of interpersonal environment on burnout and organizational commitment. Journal of Organizational Behavior, 9(4). 297-308. doi:10.1002/job.4030090402

Leiter, M. P., \& Maslach, C. (2004). Areas of work-life: A structured approach to organizational predictors of job burnout. In P. L. Perrewe, D. C. Ganster (Ed.), Research in Occupational Stress and Well Being 3, (p. 91-134). doi:10.1016/S1479-3555(03)03003-8

Maenner MJ, Shaw KA, Baio J, Washington, A., Patrick, M., DiRienzo, M., ... Christensen, D. L. (2020). Prevalence of Autism Spectrum Disorder Among Children Aged 8 Years-Autism and Developmental Disabilities Monitoring Network, 11 Sites, United States, 2016. MMWR Surveillance Summaries, 69(No. SS-4).

$1-12$. doi:10.15585/mmwr.ss6904a1

Maslach, C., \& Jackson, S. E. (1981). The measurement of experienced burnout. Journal of Occupational Behavior, 2. 99-113. doi:10.1002/job.4030020205

Patten, S. B., Williams, J. V. A., Lavorato, D. H., \& Eliasziw, M. (2009). A longitudinal community study of major depression and physical activity. General Hospital Psychiatry, 31(6), 571-575. doi:10.1016/j.genhosppsych.2009.08.001

Russell, R. V. (1987). The Importance of Recreation Satisfaction and Activity Participation to the Life Satisfaction of Age-segregated Retirees. Journal of Leisure Research, 19(4). 273-283. doi:10.1080/00222216.1987.11969698.

Russell, R. V. (1990). Recreation and Quality of Life in Old Age: A Causal Analysis. Journal of Applied Gerontology, 9(1). 77-90. doi:10.1177/073346489000900107

Şahin, C. (2010). Examination of correlation between depression and hopelessness levels in mothers of children who attend rehabilitation centers. Procedia-Social and Behavioral Sciences, 2(2), 5100-5103. doi:10.1016/j.sbspro.2010.03.828

Sayer, L. C. (2005). Gender, time and inequality: Trends in women's and men's paid work, unpaid work and free time. Social Forces, 84(1), 285-303.

Sikora, D., Moran, E., Orlich, F., Hall, T. A., Kovacs, E. A., Delahaye, J., ... Kuhlthau, K. (2013). The relationship between family functioning and behavior problems in children with autism spectrum disorders. Research in Autism Spectrum Disorders, 7(2), 307-315. doi:10.1016/j.rasd.2012.09.006

Singh, J., Goolsby, J. R., \& Rhoads, G K. (1994). Behavioral and Psychological Consequences of Boundary Spanning Burnout for Customer Service Representatives. Journal of Marketing Research, 31(4), 558-569. doi: $10.1177 / 002224379403100409$

Şireli, Ö., \& Soykan, A., A. (2016). Examination of relation between parental acceptance-rejection and family functioning in adolescents with depression. Journal of Psychiatry, 17(5), 403410. doi:10.5455/apd.179441

Sylvester C. (2014) Therapeutic recreation and disability studies: Seeking an alliance. Therapeutic Recreation Journal, 48(1). 46-60.

Tel, H., \& Ertekin-Pınar, Ş. (2013). Investigation of relationship in between burnout and depression in primary caregivers of chronic mental problem patients. Journal of Psychiatric Nursing, 4(3), 145-152 doi:10.5505/phd.2013.58088

Toker, S., \& Biron, M. (2012). Job burnout and depression: Unraveling their temporal relationship and considering the role of physical activity. Journal of Applied Psychology, 97(3), 699-710. doi:10.1037/a0026914

Tunçel, A. (2017). Comparison of the levels of depression, burnout, and hopelessness of the mothers of children with autism spectrum disorders according to the severity of autism in the child. (Unpublished Master Thesis). Hasan Kalyoncu University, Gaziantep.

Tunçel, A., Tar1-Cömert, I., \& Semerci, B. (2018). Determining Maslach Burnout Inventory usability of parents of autistic spectrum disorder children. Anatolian Journal of Psychiatry, 19(2), 64-71. doi:10.5455/apd.295975

Turnbull, A., Turnbull, R., Erwin, E. \& Soodak, L. (2007). Families, professionals, and exceptionality positive outcomes through partnerships and trust (5.ed.). New Jersey: Pearson.

Tütüncü Ö., \& Aydın İ. (2016). Examining of recreation therapy camps within the scope of tourism without disabilities [Turkish]. Anatolia: 
Journal of Tourism Research, 27(2), 290-297. https://www.anatoliajournal.com/atad/depo/der giler/Cilt27_Sayi2_Yil2016_1484086518.pdf

Tütüncü, Ö. (2012). The Role of Recreation and Recreation Therapy in Quality of Life [Turkish]. Anatolia: Journal of Tourism Research, 32(2), 248-252. https://dergipark.org.tr/en/download/articl e-file/154442

Vella E.J., Milligan B., \& Bennett J. L. (2013). Participation in Outdoor Recreation Program Predicts Improved Psychosocial Well-Being Among Veterans with Post-Traumatic Stress Disorder: A Pilot Study, Military Medicine, 178(3), 254-260. doi:10.7205/MILMED-D-12-00308

Weiss M. J. (2002). Harrdiness and social support as predictors of stress in mothers of typical children, children with autism, and children with mental retardation. Autism: The International Journal of Research and Practice, 6(1), 115-130. https://doi.org/10.1177/136236130200600100 9

Williams K. E., \& Bond, M. J. (2002). The roles of selfefficacy, outcome expectancies and social support in the self-care behaviors of diabetes. Psychology, Health \& Medicine, 7(2), 127141. doi:10.1080/13548500120116076

How to cite this article: Şahin, E., Öz, A.O., Özdurak Singın, R.H. and Düz, S. (2020). The Effects of Recreational Activities on Depressive Symptoms and Burnout Level of Mothers of Children with Autism Spectrum Disorders. Int $J$ Disabil Sports Health Sci;3(2):74-82. https://doi.org/10.33438/ijdshs. 754440 